\title{
APRENDIZAGEM SITUADA, PARTICIPAÇÃO E LEGITIMIDADE NAS PRÁTICAS DE
}

\section{TRABALHO}

\section{LUCAS SOCOLOSIK GUDOLLE}

Mestre em Administração pela Faculdade de Administração da Universidade Federal do Rio Grande do Sul (UFRGS).

Professor da Faculdade de Administração do Grupo Educacional Unificado. Avenida Alberto Bins, 467, Centro, Porto Alegre - RS - Brasil - CEP 90030-140

E-mail: lucasgudolle@yahoo.com.br

\section{CLAUDIA SIMONE ANTONELLO}

Doutora em Administração pelo Departamento de Ciências Administrativas da Universidade Federal do Rio Grande do Sul (UFRGS).

Professora do Departamento de Ciências Administrativas da Universidade Federal do Estado do Rio Grande do Sul (UFRGS). Rua Washington Luís, 855, sala 315, Centro, Porto Alegre - RS - Brasil - CEP 90010-460 E-mail: csantonello@ea.ufrgs.br

\section{LEONARDO FLACH}

Doutor em Administração pelo Departamento de Ciências Administrativas da Universidade Federal do Estado do Rio Grande do Sul (UFRGS).

Professor do Departamento de Ciências Contábeis da

Universidade Federal de Santa Catarina (UFSC).

Rua Professor João David Ferreira Lima, campus universitário, Trindade,

Florianópolis - SC - Brasil - CEP 88034-520

E-mail: leoflach@cse.ufsc.br

Este artigo pode ser copiado, distribuído, exibido, transmitido ou adaptado desde que citados, de forma clara e explícita, o nome da revista, a edição, o ano e as páginas nas quais o artigo foi publicado originalmente, mas sem sugerir que a RAM endosse a reutilização do artigo. Esse termo de licenciamento deve ser explicitado para os casos de reutilização ou distribuição para terceiros. Não é permitido o uso para fins comerciais. 


\section{RESUMO}

O presente estudo tem por objetivo identificar e analisar o processo de aprendizagem situada a partir da participação e legitimidade nas práticas dos grupos de trabalho da Dublin Irish Pub. O arcabouço teórico envolve a aprendizagem situada, aprofundada junto com o estudo da participação periférica legitimada e diferentes níveis de participação nas práticas de trabalho dos grupos de trabalho. Com base no método qualitativo básico, a coleta de dados ocorreu por observação direta, diário de campo, entrevistas em profundidade. O período de observação de seis meses totalizou 32 idas a campo e oito entrevistas realizadas na empresa estudada. Assim, por meio da análise interpretativista, as informações da pesquisa permitem elucidar de que maneira a participação e legitimidade nas práticas de trabalho podem auxiliar na aprendizagem. Entre os resultados encontrados no estudo, destacam-se as formas de aprendizagem situada que surgiram em três grupos: garçons, barmen e cozinha. Descrevendo de forma analítica o engajamento e participação dos aprendizes nas práticas de trabalho e nas comunidades de prática, argumenta-se, com base neste trabalho, que esse processo de atuação nas comunidades de prática passa pela fase inicial de participação periférica legitimada, já que, a partir do engajamento e da atuação com os mais experientes, desenvolve-se a aprendizagem. Além disso, os ganhos de legitimidade e pertencimento são elementos relevantes no processo de aprendizagem, e pode-se identificar que o processo de aprendizagem situada não ocorre somente em comunidades de prática e que o pertencimento e a participação periférica legitimada são características a serem fomentadas nas organizações. A partir da negociação e renegociação de significados, pelo estabelecimento de relacionamentos sociais e comunidades de prática, cria-se um sistema por meio do qual os modos de ver, interpretar, compreender e praticar se constituem e são compartilhados.

\section{PALAVRAS-CHAVE}

Aprendizagem situada; Participação; Práticas de trabalho; Comunidades de prática; Legitimidade. 


\section{INTRODUÇÃO}

O presente estudo tem por objetivo identificar e analisar o processo de aprendizagem a partir da participação e legitimidade nas práticas dos grupos de trabalho da Dublin Irish Pub. A teoria da aprendizagem situada e o conceito de comunidades de prática de Lave e Wenger (I99I) possibilitaram avanços em diversas áreas do conhecimento para a explicação dos processos de aprendizagem e também sobre como a aprendizagem pode ser construída a partir das práticas de trabalho e das formas como os aprendizes adquirem práticas e se relacionam com os mais experientes no ambiente de trabalho. No entanto, esse conceito também se tornou muito amplo, sendo estendido para a denominação de diversos grupos de trabalho e grupos virtuais. Dessa forma, percebe-se a necessidade de voltar à interpretação do significado atribuído nos estudos seminais de Lave e Wenger (I99I). Assim, este trabalho auxilia na manutenção de um debate sobre os conceitos de aprendizagem situada e comunidades de prática, focando especificamente a forma de participação e o engajamento dos indivíduos nos grupos.

Recentes estudos e grupos de pesquisa têm procurado compreender, com base na teoria da aprendizagem situada, a articulação entre contexto, participação, identidade e aprendizagem nas organizações. Destacam-se os seguintes estudos:

- Hong e O (2009) analisaram conflitos de identidade e poder com base na teoria da aprendizagem situada.

- Swan, Scarbrough e Robertson (2002), também embasados na teoria da aprendizagem situada, identificaram a formação de comunidades de prática em uma instituição do México que busca método inovador para o tratamento do câncer.

- Souza-Silva (2009), em estudo de casos múltiplos com quatro universidades, analisou as condições e os desafios para o surgimento de comunidades de prática.

- Antonello e Ruas (2005) utilizaram a noção de comunidades de prática como concepção para programas de ensino em administração, especialmente pós-graduação lato sensu, como uma tentativa de articular formação gerencial, aprendizagem em ação e desenvolvimento de competências gerenciais.

- Handley et al. (2007) procuraram identificar como consultores aprendem práticas e formam identidades em seus projetos.

- Sturdy et al. (2006) compararam a aprendizagem com a formação da identidade em um curso de especialização em administração. 


\section{APRENDIZAGEM SITUADA E PARTICIPAÇÃo PERIFÉrica LEGITIIMADA}

A aprendizagem, na visão da teoria da aprendizagem situada, é entendida como uma atividade ligada ao contexto e que possui como característica fundamental um processo denominado participação periférica legitimada (LAVE; WENGER, I99I). Lave e Wenger (I99I) propõem que a aprendizagem é um processo de participação em comunidades de prática, participação esta que é inicialmente periférica legitimada e gradualmente aumenta em complexidade e engajamento. Nessa teoria, os aprendizes inevitavelmente participam em comunidades, e a aprendizagem ocorre quando os novos membros começam a dominar as habilidades e demonstram atitudes nas quais se percebe claramente que a participação deles se tornou legítima.

Essa perspectiva teórica enfatiza o aprendizado como um entendimento social e histórico-cultural que compreende a pessoa em sua totalidade, na sua relação com a comunidade em que se situa, e não como um ser que se sujeita ao papel de receptor de um corpo de conhecimento sobre fatos relacionados ao mundo (SENSE; BADHAM, 2008). Assim, a abordagem da aprendizagem situada busca entender a atividade dentro do mundo e com ele, vislumbrando o agente, a atividade e o mundo como mutuamente constitutivos e inter-relacionados.

Em determinados momentos, situar significa localizar os pensamentos e as ações das pessoas no tempo e no espaço. Em outras ocasiões, o pensamento e a ação adquirem significado somente nas circunstâncias em que ocorrem, ou seja, dependem do contexto social que os ocasionou (LAVE; WENGER, I99I). Situar também implica não generalizar. Um conhecimento que é generalizado não tem privilégio sobre outros tipos de conhecimento, uma vez que todo conhecimento tem sua relevância e a generalização somente pode ser alcançada em circunstâncias específicas (SENSE; BADHAM, 2008). Assim, qualquer forma de conhecimento se situa no poder para renegociar o significado do passado e do futuro, para construir o significado das circunstâncias do presente (LAVE, I99I). Reforça-se também a necessidade de localizar onde ocorre a aprendizagem, contextualizando-a e situando-a, apresentando suas peculiaridades sociais, históricas, culturais, econômicas e políticas, de modo que as circunstâncias analisadas sejam delimitadas com o objetivo de não descolar o processo de aprendizagem do lócus em que ocorre. Afinal, "o significado não existe dentro de nós nem no mundo exterior, mas na relação dinâmica da vivência no mundo" (WENGER, I998, p. 54). Desse modo, a integração entre aprendizagens formal e informal é necessária para a criação das capacidades, tanto no indivíduo como no grupo 
(SVENSSON; ELLSTRÖM; ÅBERG, 2004). Na verdade, apesar de a aprendizagem situada enfocar a aprendizagem informal, essa teoria não pretende realizar tal dissociação, mas manter uma coerência com outros estudos acadêmicos já realizados:

Há uma tendência forte para perceber a aprendizagem informal e formal como separadas. Isto resulta frequentemente numa polarização entre elas; [...] a visão dominante na literatura é buscar identificar atributos e características que possam separar radicalmente aprendizagem formal da informal. Esta é uma abordagem equivocada, pois o mais importante é identificar sua integração. Desta forma, o desafio está na verdade em reconhecer e identificar os atributos e entender suas implicações (ANTONELLO, 2004, p. 3).

No contexto em que o processo social de aprendizagem ocorre, o diálogo, a observação, as histórias contadas e as conversas entre as pessoas são elementos que implicam diretamente os comportamentos de aprendizagem dos membros em comunidades de prática, carregando influências ambientais e socioculturais. As comunidades de prática (CoPs) são essencialmente grupos de pessoas que compartilham uma preocupação ou uma paixão por algo que fazem e procuram aprimorar cada vez mais suas habilidades por meio de trocas de experiências (WENGER, 2000), buscando soluções para uma classe comum de problemas e incorporando, consequentemente, um estoque de conhecimento (LAVE; WENGER, I99I). Uma CoP pode ser definida, dessa forma, pela existência de um tópico de interesse, pela possibilidade de interação e relações entre os indivíduos em torno do tópico e, finalmente, por haver uma prática e não meramente um interesse compartilhado (ANTONELLO; RUAS, 2005).

Cada comunidade de prática possui um domínio que representa a área de conhecimento em torno da qual convergem os interesses dos membros da comunidade, constituindo uma base comum e um senso de identidade. Bem definido, o domínio legitima a comunidade pela afirmação dos propósitos e valores dos membros e de outros atores interessados (WENGER; SNYDER, 2000). Nesse sentido, a participação e interação das pessoas nas atividades coletivas também adquirem importância analítica, pelo próprio desenvolvimento humano a partir da interação social e do pertencimento a comunidades de prática (LAVE; WENGER, I99I; WENGER, I998).

A participação encontra-se sempre baseada em uma negociação situada e renegociação de significados no mundo. Isso implica que entendimento e experiência estão em constante interação e são mutuamente constitutivos. Então, "a compreensão da aprendizagem nos termos da participação concentra-se na evo- 
lução desta e no conjunto de relações que é constantemente renovado" (LAVE; WENGER, I99I, p. 50). Essa articulação entre participação e aprendizagem dissolve a dicotomia entre atividade cerebral e corporal, entre contemplação e envolvimento, entre abstração e experiência: "pessoas, ações e o mundo estão implicados em todos os pensamentos, expressões, conhecimento e aprendizagem" (LAVE; WENGER, I99I, p. 52).

Seja ela subjetiva ou objetiva, a participação numa prática social sugere um foco explícito sobre a pessoa, como integrante de uma comunidade sociocultural. Aprendizagem pela participação envolve a pessoa como um todo, o que sugere não somente uma relação com atividades específicas, como também uma relação com comunidades sociais, e implica tornar-se um participante pleno, um membro reconhecido na comunidade. A aprendizagem pela participação nas práticas torna possível se envolver em novas atividades, realizar novas tarefas e funções para dominar novos entendimentos. Atividades, tarefas, funções e entendimentos não existem isoladamente. Aprendizagem, assim, implica tornar-se uma pessoa diferente com respeito às possibilidades abertas por esse sistema de relações. Ignorar esse aspecto da aprendizagem é menosprezar o fato de que a aprendizagem envolve a construção de identidades (LAVE; WENGER, I99I).

Lave e Wenger (I99I) sugerem o conceito de currículo de aprendizagem, considerando que, nos grupos que compartilham práticas de trabalho, existem fontes de aprendizado essenciais, vivenciadas a partir do cotidiano e das trocas relacionais, no contato entre os aprendizes e os mais experientes. Com o passar do tempo, suas aprendizagens acumulam, passando a participar do ofício com a legitimação e aproximação ao núcleo. Aprofundando as ideias de participação e aprendizagem situada, Gherardi, Nicolini e Odella (I998, p. 280) desenvolveram o conceito de currículo situado:

Introduzimos o conceito de currículo situado para denotar o modelo de oportunidade de aprendizagem disponível para os novatos em seu encontro com uma comunidade específica dentro de uma organização específica. Enquanto o currículo de aprendizagem foca as oportunidades de aprendizado relacionadas a uma ocupação específica, a noção de currículo situado enfatiza o fato que seu conteúdo está intimamente relacionado com um conjunto específico de características materiais, econômicas, simbólicas e sociais do sistema de prática e atividades de trabalho.

Portanto, a dimensão da prática social é enfatizada na teoria da aprendizagem situada, que compreende a aprendizagem como indissociável das circunstâncias de sua aquisição, não sendo algo que possa ser descolado de um contexto 
e colado em outro, pois a ação de aprender ocorre pelo simbolismo situado nas interações do grupo em um contexto específico e no decorrer de determinado intervalo de tempo. Essa prática social envolve participação nas atividades de trabalho, ou seja, envolve engajamento mútuo e não depende apenas do simples desempenho efetivo das tarefas. Isto é, a aprendizagem situada envolve a participação dos membros do grupo no compartilhamento de ideias para a resolução de problemas (BROWN; DUGUID, I99I).

A participação periférica ocorre por causa das múltiplas e diferentes formas de engajamento dos membros no grupo, bem como pelos seus modos de alocação nos campos de participação definidos pela comunidade de prática. Lee e Roth (2003) propõem que participar perifericamente é ser alocado no mundo social. As mudanças na localização e perspectivas são partes da trajetória de aprendizagem dos atores envolvidos, bem como o desenvolvimento de identidades e formas de afiliação. Esse desenvolvimento da identidade é um processo que ocorre por meio do engajamento em uma comunidade de prática, pelo processo de participação periférica legitimada. Esse conceito resgata a ideia da figura do aprendiz, pois é uma forma de falar sobre as relações entre novatos e veteranos, e sobre atividades, identidades, artefatos e comunidades de prática (LAVE; WENGER, I99I).

Entretanto, não há um lugar na comunidade de prática denominado periferia, assim como não há unicamente um centro ou uma essência. Lave e Wenger (I99I) sugerem, no entanto, o conceito de participação plena, que envolve o domínio do conhecimento e de práticas coletivas, para fazer justiça à diversidade de relações envolvidas nas diferentes formas de participação num grupo de trabalho. Mesmo assim, a participação periférica não significa uma participação parcial em comparação com a participação plena. Participação periférica sugere uma abertura, um modo de obter acesso a fontes para entendimento da prática por meio de um envolvimento crescente com os membros da comunidade de prática. A participação periférica legitimada não é uma forma educacional, muito menos uma estratégia pedagógica ou uma técnica de ensino, sob um ponto de vista analítico a respeito da aprendizagem, pois se trata de um modo de compreensão da aprendizagem imbricado nas práticas sociais da comunidade de prática (LAVE; WENGER, I99I).

Participação periférica legitimada, portanto, refere-se ao desenvolvimento de identidades por meio das habilidades conhecidas na prática, da reprodução delas e da transformação das comunidades de prática. Interessa também aos novatos compreender como as comunidades de prática são constituídas, uma vez que essa compreensão perpassa a identidade de seus membros, incluindo suas características biográficas, seus relacionamentos e práticas (LAVE; WENGER, I99I). Visualizar aprendizagem como participação periférica legitimada 
significa que aprendizagem não é meramente uma condição para tornar-se um membro, mas é em si uma forma envolvente de tornar-se um membro.

Há quatro elementos da teoria da aprendizagem situada pela participação periférica legitimada que necessitam ser aprofundados: pertencimento para aprendizagem, participação legitimada, periferalidade e comunidade de prática.

Primeiro, o processo de aprendizagem é sempre imbricado no social, o que não implica necessariamente que toda aprendizagem é uma atividade em grupo, mas no reconhecimento de que os indivíduos estão necessariamente envolvidos em relações materiais e sociais. Lave e Wenger (I99I) asseveram que esse argumento é a consciência de onde a aprendizagem está acontecendo e o seu papel nos meios de produção e reprodução social, num tempo e espaço particular. Também implica que a aprendizagem de habilidades já conhecidas é mediada pela experiência de participação dos membros e pelo pertencimento numa comunidade de prática.

Já a participação legitimada sugere que a participação dos novos membros é uma contribuição legítima para sua comunidade de prática. Na perspectiva da participação periférica legitimada, as atividades de tais membros são práticas legítimas de reproduzir a cultura da organização. A legitimidade da participação é uma característica determinante dos modos de pertencimento e não é somente uma condição crucial para a aprendizagem, como também um elemento constitutivo de seu conteúdo. O trabalho deve ser realizado de modo que as práticas nas quais estão engajados sejam relevantes ao grupo de trabalho para o qual os novos membros estão sendo preparados ostensivamente (LAVE; WENGER, I99I).

Outro elemento que necessita ser destacado é a periferalidade, que significa considerar a participação dos membros parte de uma rede ou comunidade de prática e, assim, parte de um esforço coletivo. Periférico não significa indicar que um novo membro possui uma posição subordinada em relação a um antigo membro, que seria mais central. O termo é entendido como uma unidade de análise na qual a participação dos membros é legítima e periférica para o funcionamento do grupo como um todo (LAVE; WENGER, I99I). A direção da aprendizagem no modelo de participação periférica legitimada aponta para a participação plena, o que representa não apenas o domínio do conjunto de habilidades do grupo, mas também o pertencimento na comunidade, uma habilidade para participar cada vez mais das práticas comuns (LEE; ROTH, 2003).

O último elemento - comunidades de prática - articula elementos humanos e não humanos que são parte das atividades das quais os membros visam participar, contribuindo com o grupo. A comunidade de prática também se inclui no contexto que dota de significado os aspectos das práticas do grupo. A aprendizagem é situada, uma vez que seu foco está centrado sobre o modo como a participação dos indivíduos se torna plena numa comunidade de prática. Como 
um conjunto de relações entre pessoas, atividade e o mundo, a comunidade de prática consiste em uma condição intrínseca para a existência do conhecimento, envolvendo também relações de poder e legitimação (LAVE; WENGER, I99I).

O ciclo de desenvolvimento que reproduz os grupos domésticos e outras comunidades de prática, as relações dos novatos com aqueles que são adeptos e o modo como a divisão do trabalho articula os vários tipos de comunidades de práticas moldam a identidade que deve ser construída e conhecida pelos membros do grupo. Em uma comunidade de prática, o processo de reprodução da comunidade deve ser decifrado para entender as formas específicas da participação periférica legitimada através do tempo. Isso requer um amplo conceito da biografia individual e coletiva, mais do que apenas um simples estudo dos aprendizes e uma análise das modificações nas suas formas de participação e identidade das pessoas que estão engajadas em participar de uma comunidade de prática. A entrada como novato, o fato de tornar-se um veterano em relação aos novos novatos, até se tornar um veterano de fato. Melhor do que a relação professor/ aprendiz, há uma diversidade de atores no campo e, com isso, outras formas de relacionamento e participação. Em uma comunidade de prática, as interações ocorrem de diversos modos: "a comunidade de prática interage com o aprendiz, os jovens mestres com aprendizes, os jovens mestres tornando-se mestres e os novatos veteranos em relação aos novos novatos" (LAVE; WENGER, I99I, p. 56).

Nas práticas de trabalho, os indivíduos compartilham interesses ou paixões por algo que fazem e pretendem aprender como fazer melhor a partir do momento que interagem regularmente, criando comunidades de prática como os seguintes exemplos: um grupo de artistas procurando novas formas de expressão; um grupo de engenheiros trabalhando em problemas similares; uma rede de cirurgiões explorando técnicas inovadoras (WENGER, 2000). Qualquer tentativa de analisar uma forma de aprendizagem por meio da participação periférica legitimada deve envolver a análise da organização política e social dessa forma de aprendizagem e seu desenvolvimento histórico, de modo que se identifiquem os efeitos sobre as possibilidades de aprendizagem. A necessidade para tal análise motiva o foco sobre comunidades de prática e sobre a insistência de que os aprendizes devem ser participantes periféricos legitimados nas práticas para que a aprendizagem e consequente mudança na identidade por meio do engajamento proporcionem o desenvolvimento do membro até que ele participe plenamente (LAVE; WENGER, I99I).

Com base em estudos com parteiras (México), alfaiates (Libéria), marinheiros (Estados Unidos), açougueiros de supermercado (Estados Unidos) e alcoólicos anônimos (Estados Unidos), Lave e Wenger (I99I) perceberam diferentes formas de aprendizagem, de acordo com a articulação entre o fluxo de informações nas tarefas e as trajetórias das pessoas por meio de diferentes formas de 
participação nas tarefas, considerando que a questão do acesso aos aprendizes é um dos principais recursos para a aprendizagem. A importância da linguagem é outro elemento que não pode ser desconsiderado, uma vez que ela é parte da prática, e, por meio da conversa, é possível ocorrer uma construção de identidade, já que o diálogo é um meio de transformação, e é na prática que as pessoas aprendem. Além de a atividade, linguagem, motivação e identidade serem elementos centrais, a questão do acesso à prática é também um recurso fundamental para a aprendizagem e, ao mesmo tempo, um problema, pois o acesso está imbricado nas formas conflituosas da prática diária, da motivação e do desenvolvimento de identidade dos membros (LAVE; WENGER, I99I).

Handley et al. (2007) defendem que é por meio da participação que a prática e a identidade se desenvolvem, pois a participação permite ou restringe as oportunidades para desenvolver identidades e práticas, incluindo as práticas de linguagem. Entretanto, as mudanças na identidade de um indivíduo e em suas práticas podem influenciar a procura por novas oportunidades de participação.

No entanto, Lave (I993) explica que essa relação entre a participação periférica e participação plena (core, no núcleo da comunidade) não necessita ser tomada de maneira excessivamente dicotômica. Para a autora, o modo de participação pode envolver outras trajetórias de aprendizagem que não conduzem necessariamente a uma participação "plena" idealizada. A autora utiliza os conceitos de recém-chegado (newcomer) e sênior (oldtimer) para explicar a participação dos indivíduos em uma comunidade ao longo do tempo, mas não pretende argumentar que o recém-chegado tenha necessariamente o status de um novato ou inexperiente. De fato, Handley et al. (2007) destacam que não é pretensão da aprendizagem situada defender a inexistência de movimentos e circulações como perito em determinadas atividades. Wenger (I998) identificou várias formas de participação, em que as participações periférica e plena se contrastam com as marginais. O autor também introduziu formas não legítimas, bem como identificou a sobreposição e multiplicação das comunidades. Esses argumentos são importantes, pois, assim como não há espaço nas comunidades e nas organizações para que todos os indivíduos tenham participação plena, muitos aprendizes não aspiram a ela.

Para Bogenrieder (2002), a aprendizagem organizacional é frequentemente entendida do ponto de vista da soma de atividades cognitivas individuais, mas, na estrutura organizacional, somente as condições para melhoria da aprendizagem individual podem ser criadas. Dessa maneira, argumentando que a aprendizagem organizacional pode ser entendida pela soma das atividades cognitivas com as sociais, a autora propõe uma visão da aprendizagem a partir de uma arquitetura social para explicar de que modo as relações sociais interferem nos processos de aprendizagem em indivíduos, comunidades e organizações. Essa arquitetura 
social abrange o reconhecimento de que diferentes tipos de redes sociais são necessários para os vários tipos de aprendizagem (BOGENRIEDER, 2002).

A prática da comunidade cria um currículo potencial sobre o que pode ser aprendido pelo novato com acesso periférico legitimado. Há grandes objetivos para a aprendizagem porque os aprendizes, como participantes periféricos, podem desenvolver uma visão do todo da organização e o que pode ser aprendido. Aprendizagem em si é uma prática improvisada, e o currículo de aprendizagem é desdobrado não de modo específico como um conjunto de ditames para a prática, mas nas oportunidades para o engajamento dos novatos (LAVE; WENGER, I99I).

Nas oportunidades para aprendizagem, o relacionamento entre mestre e aprendiz pode ser assimétrico, com isso o aprendiz busca aprender nas interações com outros aprendizes, uma vez que a circulação de informações entre os pares sugere um engajamento na prática e é uma condição para uma efetiva aprendizagem. Após um extenso período de periferalidade legitimada, os aprendizes gradualmente entendem a ideia geral do que constitui a prática da comunidade. Para que os aprendizes tenham acesso legitimado, é fundamental que sejam capazes de identificar alguns aspectos fundamentais: quais são as pessoas envolvidas, o que elas fazem, como é a rotina delas, como conversam, como trabalham e conduzem a vida, como as pessoas que não são parte da comunidade de prática interagem com os membros da comunidade, o que os outros aprendizes estão fazendo e o que um aprendiz precisa aprender para se tornar um participante pleno. Isso implica também entender como, quando e em quais circunstâncias os veteranos colaboram com os novatos, confiam neles e os acolhem, além de conhecer o que os veteranos apreciam, refutam, respeitam e defendem. Isso oferece razões e motivações exemplares para o processo de tornar-se um participante pleno (LAVE; WENGER, I99I).

A participação tem múltiplos níveis em uma comunidade de prática, pois a participação ocorre em um sistema de atividades, em que os participantes compartilham entendimentos sobre o que estão fazendo e o significado dessas atividades na vida deles e para as comunidades a que pertencem. Melhor do que replicar as performances dos outros ou adquirir conhecimento transmitido pela instrução, a teoria sugere que a aprendizagem ocorre por meio da participação no currículo de aprendizagem, no ambiente da comunidade (LAVE; WENGER, I99I).

Enfim, a participação periférica legitimada é um conceito fundamental das relações de aprendizagem que ocorrem nas práticas culturais, nas questões de acesso e na transparência do ambiente cultural com respeito ao significado que está sendo aprendido. Aprender a tornar-se um participante legitimado em uma comunidade envolve aprender como falar e a estar em silêncio na maneira dos participantes plenos. Porém, para os novatos, o propósito não é aprender a partir 
das conversas, como uma forma de substituição para a participação periférica legitimada, e sim aprender para conversar como um participante pleno (LAVE; WENGER, I99I).

Participação periférica legitimada é uma forma inicial de ser um membro característico de uma comunidade, e a aceitação e a interação com o reconhecimento por parte dos adeptos da comunidade legitimam a aprendizagem dos novatos. Para poder participar de um modo periférico legitimado, o novato deve ter amplo acesso às áreas onde ocorrem as práticas, porém, ao mesmo tempo, uma periferalidade produtiva requer menor demanda, esforço e responsabilidade para o trabalho em relação aos participantes plenos. As tarefas dos novatos são simples e curtas, o custo de possíveis erros é pequeno e o aprendiz tem menos responsabilidade nas etapas das atividades em que está envolvido (LAVE; WENGER, I99I).

Movimentar-se para a participação plena na prática envolve não apenas um grande compromisso de tempo, intensificado esforço, maiores e amplas responsabilidades dentro da comunidade e tarefas mais difíceis e arriscadas, mas, principalmente, um crescente sentimento de identidade como participante pleno. A aprendizagem deve ser entendida com respeito à prática como um todo, com suas múltiplas relações dentro da comunidade e com o mundo em geral. Desassociar a aprendizagem das intenções pedagógicas abre a possibilidade de disputas e conflitos entre os pontos de vista dos praticantes nas situações em que a aprendizagem está ocorrendo. Essa diferença frequentemente se torna constitutiva do conteúdo da aprendizagem (LAVE; WENGER, I99I).

Portanto, participação periférica legitimada é mais do que apenas um processo de aprendizagem por parte dos novatos. É uma relação recíproca entre pessoas e prática. Isso significa que, quando os aprendizes se movem para a participação plena, a comunidade de prática não está em um contexto estático, a prática em si está em movimento. Periferalidade legitimada é importante para desenvolver perspectivas ou questões ingênuas. Desse ponto de vista, a inexperiência é um trunfo a ser explorado, porém somente no contexto da participação, quando auxiliados por participantes experientes que entendem suas limitações e valorizam seu papel. Legitimidade da participação é crucial também para esse envolvimento ingênuo, o qual sugere a reflexão sobre as atividades que estão ocorrendo e que proporciona contribuições ocasionais a serem levadas em conta. Na medida em que essas interações contínuas de novas perspectivas são sancionadas, todas as formas de participação são legitimadas periféricas em alguns aspectos. Em outras palavras, todos podem, em algum grau, ser considerados novatos para o futuro de uma comunidade em constante mudança (LAVE; WENGER, I99I). 


\section{PROCEDIMENTO METODOLÓGICO}

A pesquisa qualitativa adotada nesta pesquisa ajuda a compreender e explicar o significado dos fenômenos sociais com uma pequena perturbação da configuração natural (MERRIAM, I998). Nessa concepção, foca-se o interesse no entendimento do significado que as pessoas têm construído, como elas tomam sentido de seu mundo e as experiências que desenvolvem por meio de sua interação no mundo e com seus elementos (MERRIAM, I998). A pesquisa qualitativa sustenta que o significado está imbricado nas experiências das pessoas e que esse significado é mediado pelas próprias percepções do investigador.

Merriam (I998) propõe cinco características que, segundo ele, são comuns a todos os tipos de pesquisa qualitativa. Como primeira característica, observa que os pesquisadores qualitativos têm interesse no entendimento do significado que as pessoas constroem, ou seja, o entendimento conforme a perspectiva dos participantes e não a do pesquisador, do êmico e não do ético. A segunda característica é que o pesquisador é o instrumento primário para a coleta de dados e faz sua análise posterior ou simultaneamente. A terceira característica observada consiste em que, usualmente, o estudo qualitativo envolve trabalho de campo. A quarta característica da pesquisa qualitativa é o emprego de uma estratégia de pesquisa indutiva. Por fim, sua quinta e última característica é focar o processo, significado e entendimento. Dessa forma, o produto do estudo qualitativo é ricamente descritivo. O presente estudo atende às características supramencionadas, uma vez que tem interesse no entendimento dos significados que o grupo constrói, além de resultar de trabalho de campo, no qual o pesquisador é o principal instrumento de coleta e análise de dados. Análise esta que, por sua vez, é essencialmente indutiva. Segundo Merriam (I998), entre as características principais do estudo qualitativo básico ou genérico, incluem-se: a descrição, interpretação e compreensão; a utilização de dados obtidos por meio de entrevistas, observações e análise documental; a identificação de padrões recorrentes por meio da análise dos dados, como temas, categorias, fatores e variáveis; e a preocupação na descoberta e compreensão de um fenômeno, processo, perspectiva e visões dos pesquisados.

A coleta de dados ocorreu por observação direta, diário de campo e entrevistas em profundidade. O período de observação de seis meses totalizou 32 idas a campo e oito entrevistas realizadas na empresa Dublin Irish Pub. Focou-se a análise da aprendizagem em três grupos: garçons e garçonetes, barmen e cozinha e serviços gastronômicos. A caracterização geral da organização e administração da Dublin Irish Pub foi possibilitada a partir de entrevista realizada com a gerente da empresa, quando também se efetuou o primeiro contato a fim de obter 
autorização para realizar o estudo. Os dados coletados nas entrevistas remeteram aos seguintes tópicos de análise: história da organização, serviços, proposta da organização, ambientes da organização, clientes e grupo de trabalho.

A observação direta consiste em uma técnica da qual se valem principalmente cientistas sociais ao realizarem trabalho de campo. Seu objetivo não é somente situar o pesquisador no lócus de investigação, mas também trazer à tona elementos que não se fazem presentes no discurso dos informantes (RYAN; BERNARD, 2000). O relato da observação pode tanto ser incorporado aos resultados de pesquisa quanto ser utilizado como suporte ao processo de análise e interpretação dos dados oriundos de campo. Os papéis assumidos pelo pesquisador durante a observação direta foram variados: em alguns momentos, esteve no papel de cliente, acompanhou, em outros, o atendimento aos clientes e também participou de reuniões. Esses papéis podem variar de acordo com a abertura que será concedida pelos pesquisados.

O diário de campo está associado diretamente à técnica de observação, uma vez que são registradas nele as experiências e os fatos acontecidos no levantamento dos dados durante a estada em campo. Considerando os seis meses de trabalho de campo, num total de 32 idas a campo, tornou-se importante que, além do observado em campo, fossem anotadas as impressões e percepções do pesquisador. Ou seja, como o pesquisador interpretou o fenômeno observado no momento específico em que esteve em contato com este, uma vez que o registro dos detalhes minuciosos enriquece o relatório de pesquisa, tanto com o entendimento do êmico quanto do ético (ROCHA; BARROS; PEREIRA, 2005).

Outra técnica utilizada na pesquisa foi a entrevista em profundidade. Nessa técnica, é importante colocar em prática a escuta ativa, bem como a observação da linguagem verbal e não verbal dos pesquisados. Durante a entrevista, o contato presencial permite a apreensão do ritmo de fala, hesitações, variações de emoção e voz. Já quanto à linguagem não verbal, a percepção dos gestos, da distância espacial e de outras informações corporais pode ser captada nas entrevistas realizadas pessoalmente (ROCHA; BARROS; PEREIRA, 2005). As entrevistas seguiram o formato semiestruturado, no qual os questionamentos são apoiados em alguns tópicos e elementos principais a serem abordados. Manteve-se aberta a possibilidade de improvisar questões condizentes com as respostas, viés e intenções que os entrevistados demonstraram no momento da entrevista. Essa técnica é constituída de um roteiro com perguntas abertas, organizado numa ordem prevista antecipadamente, mas que pode não ser seguida rigorosamente no momento da entrevista, podendo ainda ser acrescentadas perguntas para aprofundamento da investigação durante o processo de realização da entrevista. Durante a efetivação da entrevista, foram realizados alguns questionamentos de 
modo a suportar as questões efetuadas e buscar um melhor entendimento da posição dos entrevistados.

Os significados, entendimentos ou insights possibilitados pela análise constituem as descobertas do estudo. Essas descobertas podem ser organizadas em temas, em categorias, na forma de modelo ou, ainda, em um nível mais avançado, numa teoria substantiva. Cada uma dessas formas constitui um diferente nível de análise dos dados, desde um nível mais concreto até um mais elevado para construção de teoria. Movendo-se por meio dos níveis de análise, o desafio deste trabalho foi construir categorias que capturassem alguns padrões de recorrência capazes de demonstrar a preponderância do dado (TAYLOR; BOGDAN, I984). As categorias são "conceitos indicados pelo dado (e não o dado em si) [...]. Em suma, categorias conceituais e propriedades têm uma vida à parte da evidência em que surgem" (TAYLOR; BOGDAN, I984, p. 36).

A tarefa realizada foi comparar cada unidade de dado com a próxima, atentando para as regularidades e recorrências nos dados a fim de construir as categorias. A construção de categorias começou com a leitura da primeira entrevista transcrita, das primeiras notas no diário de campo, enfim, os primeiros dados coletados. Durante esse processo, realizaram-se comentários e observações escritas nas margens do material analisado, como se estivesse sendo conduzida uma conversa, com questões e comentários a respeito dos dados coletados. Essas notas serviram para separar os aspectos que são mais relevantes nos dados obtidos. Depois de concluída a leitura do material e feitas as anotações nas margens dos primeiros dados coletados, realizou-se uma tentativa de agrupamento de notas, comentários e questões referentes aos dados. Esse agrupamento foi registrado em uma lista que serviu de consulta para a próxima análise de transcrição ou observação comentada no diário de campo.

Concluída a análise do segundo conjunto de dados, a qual resultou em uma nova lista de notas e comentários agrupados em categorias, foi conduzida uma comparação entre ambas as listas. O resultado compôs a fonte primária para construção da lista principal de unidade de dados, que reflete as regularidades e os padrões encontrados, os quais constituem os insumos para originar as categorias de dados (MERRIAM, I998).

\section{ANÁLISE dOS DADOS E RESULTADOS DA PESQUISA}

Neste projeto, optou-se pela realização do estudo na organização Dublin Irish Pub, mais especificamente com o grupo de garçons, garçonetes, barmen e 
os responsáveis pela parte de atendimento dos serviços gastronômicos. A caracterização da organização Dublin Irish Pub ocorreu a partir de entrevista realizada com a administradora da empresa, quando houve o primeiro contato a fim de obter autorização para realização do estudo. A entrevista abordou os seguintes assuntos: história da organização, serviços, proposta da organização, ambientes da organização, clientes e grupo de trabalho.

A Dublin Irish Pub foi inaugurada no dia 25 de novembro de 2004 e está localizada na rua Padre Chagas, nㅜ 342 , no bairro Moinhos de Vento, na cidade de Porto Alegre/RS. Desde a inauguração, a casa é aberta ao público todos os dias da semana, a partir das I8 horas. A empresa é definida por sua administradora como "pub irlandês", cujo negócio compreende o serviço de gastronomia, bebida e música ao vivo no "melhor estilo irlandês". A organização, que possui porte de microempresa e é de propriedade de três sócios, surgiu a partir do desejo dos fundadores de abrir um negócio no ramo do entretenimento, como um bar. Após a realização de pesquisas, nas palavras da administradora, os sócios "se encantaram com o pub irlandês, da alegria, da descontração, das pessoas irem pra lá e beberem bastante, e, enfim, da diversão agregada, da alegria do lugar, do povo, da proposta!”. Em seguida à definição da ideia do negócio, foi escolhido o ponto de funcionamento da casa, considerado muito favorável para o sucesso do empreendimento.

Desde o início das atividades, a Dublin trabalha com o intuito de cativar o cliente com sua proposta de inovar, apostando em produtos novos, promoções e ampliações para seu público continuar instigado a retornar. Algumas das características do negócio foram moldadas conforme o gosto dos clientes, porém a Dublin adota uma série de premissas para não perder a identidade do negócio. Apesar de assumir o clima de festa, a Dublin prima pela qualidade dos produtos, comida boa e farta, bandas de qualidade, estilo musical pop rock internacional, clima de animação, bom atendimento e boa infraestrutura, características que possibilitam a continuidade do negócio, segundo a administradora.

A Dublin conta atualmente com 35 funcionários dispostos em turnos diferentes de trabalho. Nas funções desempenhadas no turno da noite, estão: um gerente, um subgerente, os caixas, um grupo de garçons, um grupo de barmen e bartenders, um porteiro, um chef de cozinha e seus auxiliares, e uma pessoa responsável pela limpeza e manutenção. Já no turno diurno, trabalham a administradora, uma relações-públicas, uma coordenadora administrativa, um estoquista, duas pessoas responsáveis pela limpeza e um porteiro. Também contam com a colaboração das bandas musicais, além de terceirizados na atividade de segurança.

A Dublin destina-se a um público adulto - de 2r a 60 anos - de classe social média ou superior. Os clientes consideram o pub um lugar democrático, onde 
é possível encontrar pessoas de todas as idades. Nos dias de maior movimento (quinta, sexta e sábado), o público predominante tem até 35 anos. A administradora do pub descreve o comportamento de consumo dos clientes:

[...] seis da tarde começa a chegar o pessoal do happy hour, aí claro verão, seis e meia a gente já tá com o deck ali da rua pelo menos cheio! [...] aí vem bastante perfil de executivo, grupo de amigas que se reúnem, a gente tem bastante de empresas, tem bastante reserva pra pessoal de banco assim, que vem direto das empresas fazer o happy hour, aí tem bastante essa característica bastante do consumo. A gente tem algumas promoções de bebida no happy hour pra estimular o consumo. Pessoal come bastante de tardezinha porque vem direto do trabalho com fome, depois tem o segundo público mais ou menos que dá pra se dizer que chega lá pelas oito e pouco nove da noite, e sai lá pela meia-noite, que vem fica um pouco no show, janta alguma coisa, mas não é assim o notívago. E tem aquela galera que vem às onze da noite e que fica pra festa, pra curtir a banda, conhecer gente bonita.

Independentemente do tipo de público supramencionado, o objetivo da empresa, segundo a administradora, é "ganhar vendendo comida e bebida, nosso negócio é vender comida e bebida. E o que a gente quer? A gente quer proporcionar um ambiente agradável e propício pra que a pessoa fique o máximo de tempo aqui consumindo e se divertindo". A Dublin, como é chamada pelos seus funcionários, é um pub que, desde sua abertura, mantém a casa cheia às quintas, às sextas e aos sábados. Sua estrutura física é composta por três ambientes: deck, térreo e mezanino. Em cada ambiente, há um bar e mesas, algumas reservadas. Na entrada, há uma pequena escada que dá acesso ao deck inferior onde há quinze mesas; subindo mais uma pequena escada, chega-se ao deck superior, com vinte mesas. No deck, as pessoas fazem o happy hour e, principalmente, jantam. Nesse local, é permitido fumar. O bar principal está localizado no térreo, onde há um palco em que as bandas tocam pop rock internacional. No mezanino, há uma mesa de sinuca, além do bar e das mesas, as quais são geralmente reservadas para aniversários e festas de empresas.

O trabalho de campo realizado teve diversos momentos: inicialmente, procurou-se identificar os grupos de trabalhos e as práticas comuns aos membros dos grupos de trabalho, e compreender a rotina semanal de trabalho da Dublin. A busca por esses dados se deu por meio das observações e interações entre o pesquisador e pesquisados. Com as mesmas técnicas supramencionadas, procurou-se aproximar dos pesquisados e explicar o objetivo da pesquisa e a importância de sua participação a fim de coletar informações e realizar as entrevistas 
para completar a coleta dos dados que viabilizassem o alcance dos objetivos deste estudo.

Para apresentação dos resultados, dividiram-se os grupos identificados: garçons, barmans e da cozinha. As práticas identificadas comuns aos grupos citados são apresentadas, bem como o processo de aprendizagem e as formas de participação e de pertencimento. Cada grupo apresenta suas peculiaridades no processo de aprendizagem, existindo também uma distinção entre as formas de participação dos recém-chegados, novatos e veteranos em cada grupo de trabalho. Neste estudo, apurou-se também que o processo de aprendizagem por meio da participação periférica legitimada ocorre nos grupos de trabalho estudados, ou seja, esse processo não ocorre apenas em comunidades de prática como sugere a teoria. Entre os achados em campo, destacam-se os diferentes processos de aprendizagem por meio da participação nas práticas de trabalho, as barreiras para o aprendizado e a relevância do pertencimento e da legitimidade.

\section{O GRUPO DOS GARÇONS: "JÁ FEZ O SEU PEDIDO?"}

No maior grupo de trabalho da Dublin, ao todo quinze funcionários que atuam em todos os ambientes da casa, existem diversos perfis de participação: recém-chegados inexperientes, recém-chegados experientes, novatos, novatos legitimados, veteranos e veteranos plenos. Os recém-chegados inexperientes e experientes na função de garçom participam perifericamente do grupo, buscando conhecer os princípios, os valores e as normas estabelecidos no grupo e aprender a postura de trabalho dos colegas, atentando à comunicação de ideias e ao engajamento dos veteranos da empresa. Os recém-chegados vivem um processo de aprendizagem situado nas práticas de trabalho desde o início de suas atividades, quando recebem a orientação do gerente quanto às funções e sobre quem será o garçom veterano que os acompanhará nos primeiros dias na casa e no setor em que trabalharão. Geralmente, os recém-chegados inexperientes iniciam seu aprendizado com atividades mais simples, como a preparação e manutenção das mesas, que envolve a reposição de guardanapos, sal, palitos, limpeza da mesa e do cinzeiro. As primeiras práticas que o garçom deve aprender são: procedimentos de preparação e manutenção das mesas, condução da bandeja, códigos dos produtos, forma de servir e retirar os pratos das mesas, identificação dos pratos e drinks mais pedidos do cardápio e formas de oferecê-los.

Os recém-chegados passam à condição de novatos não somente a partir do reconhecimento da aprendizagem das práticas mencionadas pelos veteranos e 
gestores, mas também por meio dos ganhos de legitimidade de sua participação, que ocorrem pelo aumento da confiança no seu trabalho, entendimento de seu papel na organização e de suas experiências adquiridas no seu tempo de trabalho na Dublin. Os novos recém-chegados provocam reações tanto adversas quanto favoráveis por parte de alguns novatos e veteranos. Essas reações podem ser adversas, como insegurança do emprego, desprezo e receio de se aproximar, ou favoráveis, como acolhimento, amizades e formação de casais.

Os garçons veteranos assumem a função de ensinar e auxiliar os recém-chegados, os quais devem seguir as instruções recebidas e estudar o cardápio. Quando os recém-chegados mostram domínio da bandeja, memorização dos códigos e atendimento adequado das mesas, os garçons veteranos consideram que o novato está pronto para atender ao deck inferior ou atuar no térreo. A praça mais complicada de atender é o deck inferior por causa da grande procura no happy hour e porque, nessa área, o garçom pode se confundir em razão dos constantes pedidos. Já o térreo é considerado outro ambiente de difícil atuação por causa do grande fluxo de pessoas. Nesse espaço do pub, os garçons transitam com dificuldade, fazem manobras para conduzir a bandeja, esbarram constantemente nos clientes e devem atender simultaneamente os clientes das mesas e aqueles que estão em pé.

Os garçons são considerados veteranos quando o gerente os coloca na função de treinar e supervisionar os novatos. Essa função de acompanhamento, de participação do veterano na formação do perfil profissional iniciante nas organizações, não é exercida por todos os veteranos, alguns a desempenham por ser seu estilo de trabalho, outros preferem se manter na periferalidade em relação a essa prática.

\section{O GRUPO DE ATENDENTES: BARMEN OU BARTENDERS}

O grupo de atendentes do bar representa o menor grupo de trabalho, composto por cinco funcionários: três recém-chegados, uma novata e um veterano. Esse grupo de trabalho, apesar de ser o menor, é de fundamental importância para a Dublin, porém enfrenta o problema de estar em constante formação, pois há grande rotatividade entre os recém-chegados. Apesar disso, os recém-chegados são treinados com base na participação. Inicialmente, eles aprendem as práticas mais simples, já que o trabalho do barman não se restringe a apenas atender aos pedidos dos clientes no balcão do bar. Antes de a casa abrir para o cliente, o novato deve cuidar da higiene das louças, preparar as frutas para os drinks, 
abastecer os freezers e carregar os barris de chope. Durante a noite, o novato lava a louça e ajuda, na hora do pico, os garçons, quando eles precisam de alguma bebida.

$\mathrm{Na}$ visão desses profissionais, existem diferenças entre barman e bartender. $\mathrm{O}$ barman é o profissional mais formal, sério e clássico que pratica um atendimento ortodoxo. Já o bartender não precisa usar terno e gravata e pode fugir do estilo tradicional de atuação. Em geral, os bartenders usam roupas mais descontraídas, como calça e camiseta ou aventais, e podem ter também a capacidade de divertir os clientes. O bartender também é aquele que já aprendeu e possui as práticas do flair, que consiste na realização de malabarismos com garrafas. No entanto, um bom barman ou bartender deve ter conhecimento sobre atendimento, bebidas, misturas e técnicas de preparo. Às vezes, exige-se que esse profissional domine a língua inglesa e tenha criatividade para criar drinks e receitas. Na Dublin, existem vários tipos de bebida, e o atendente deve conhecê-los e saber prepará-los. Com relação aos sucos, é preciso aprender sobre os smoothies, preparados com pedaços de frutas congeladas misturadas a sucos-base, em especialidades como o de frutas vermelhas, o havaiano e o irlandês.

O recém-chegado também é acompanhado por um veterano. As primeiras práticas aprendidas pelo barman são: procedimento de funcionamento da máquina de chope, como servi-lo, organização das garrafas para os drinks, os códigos dos produtos e a contagem das bebidas no encerramento da noite. $\mathrm{Na}$ Dublin, um barman é responsável pelo atendimento dos bares do deck e do mezanino, enquanto, no bar do térreo, há três atendentes. O recém-chegado sempre começa as atividades no bar do térreo, com acompanhamento. Após o período de aprendizado e experiência na função, ele é deslocado para um dos outros bares para aprender a atuar sozinho e dominar todas as práticas de trabalho. O novato também é treinado para assumir o bar do mezanino. A partir desse momento, o recém-chegado é considerado novato. No bar, ele obtém ganhos de participação por meio da escuta ativa, recebe feedback sobre os procedimentos e supera os limites de atuação que lhe são impostos pelos membros veteranos do grupo. Esses limites de atuação não são caracterizados como barreiras para o aprendizado, mas práticas mais complexas de serem aprendidas e que se tornam relevantes no decorrer do aprendizado. Porém, como há uma grande rotatividade dos recém-chegados, uma vez que a rotina de trabalho é muito exigente e se eles não têm experiência anterior na função, dificilmente se adaptam à rotina de trabalho, seja pelo excesso de trabalho, pela falta de responsabilidade e constantes faltas ao trabalho ou ainda pela dificuldade de conciliar a vida pessoal com a profissional. 


\section{O GRUPO DA COZINHA: MISTURANDO PRÁtICAS E OUTROS TEMPEROS}

O grupo de trabalho da cozinha é composto por seis funcionários, cujo processo de aprendizagem é diferenciado dos demais grupos. Na cozinha, há quatro praças de atuação: a dos sanduíches e aperitivos, onde se revezam dois funcionários, uma veterana e um recém-chegado; das frituras, onde trabalha um novato; das pizzas, onde trabalha outro novato; e a praça principal, onde trabalham dois veteranos, inclusive o chef de cozinha. Na cozinha, o recém-chegado atua como auxiliar: lava a louça e aprende os códigos dos pratos e o funcionamento da praça de sanduíches e aperitivos. Após o aprendizado das práticas mais simples, a primeira praça que o recém-chegado assume é a de aperitivos e sanduíches. Nesse processo inicial, o acompanhamento de um veterano é fundamental para o funcionamento da cozinha, porém cabe ao novato interessar-se em aprender todas as praças. O chef mostra como deve ser preparado o prato apenas nas primeiras vezes. O atual chef da Dublin começou como auxiliar de cozinha do pub. Sua entrada na cozinha se deu pela oportunidade de substituir um funcionário quando da sua ausência, e isso ocorria apenas quando era chamado pelo antigo chef da cozinha. Aos poucos, o atual chef obteve ganhos de legitimidade e foi aprendendo as práticas da praça que ocupava até ser contratado.

O aprendizado do funcionamento da cozinha e a movimentação entre as praças da cozinha foram a continuidade desse processo, mas ele encontrou muitas dificuldades na cozinha, principalmente aquelas impostas pelo antigo chef, que criava barreiras para o aprendizado dos demais. Por exemplo, o antigo chef rebaixava os funcionários às antigas praças que ocupavam e não incentivava o aprendizado deles. Após essa fase de restrições, o já novato e cozinheiro recebeu a oportunidade de se tornar chef da cozinha no momento em que foi demitido o antigo. Nesse momento, ele recebeu treinamento intensivo do chef responsável pela elaboração do cardápio da Dublin. Avaliou-se que a aprendizagem do chefe de cozinha ocorreu por meio da participação periférica legitimada, justificada pelos seguintes indicadores: barreiras e restrições de informações, interações constantes com os colegas da cozinha, engajamento nas atividades, reconhecimento dos superiores, ganhos de legitimidade, experiência adquirida. Nesse processo, o pertencimento é outra característica que teve destaque na aprendizagem do chef de cozinha, que afirmou: "quando descobri a cozinha e a Dublin, me senti parte daquilo tudo, descobri que era aquilo que eu queria pra mim”. Para Wenger (I998), os novos praticantes, ao participarem das práticas de trabalho, passam a pertencer a essas atividades, compartilham experiências e aprendem com elas, criam significado para o que fazem e, ao mesmo tempo, formam uma identidade. 


\section{CONSIDERAÇÕES FINAIS: "THANK YOU FOR COMING!"}

Neste estudo, foi possível apresentar o processo de aprendizagem por meio da teoria da aprendizagem situada e do processo de participação periférica legitimada. Foi identificada a formação de grupos de trabalho na organização Dublin Irish Pub, onde esse processo de aprendizagem ocorre, sendo diferenciado conforme as funções dos membros desse grupo. O pertencimento ao grupo de trabalho proporciona ganhos efetivos de legitimidade na interação entre os membros, na formação de identidade e no engajamento de novatos e veteranos.

Ressaltou-se o papel da aprendizagem coletiva a partir da análise da participação e do engajamento dos indivíduos em três grupos de trabalho: garçons, atendentes de bar e da cozinha. Cada um desses grupos aprende e desenvolve linguagens, formas de comunicação e práticas peculiares. Nesse sentido, a partir do momento que os novos membros entram nesses grupos, atuam na participação periférica legitimada (LAVE; WENGER, I99I). Mesmo assim, observou-se que muitos praticantes que entram como novatos já haviam passado por aprendizagens prévias em outros contextos e carregam consigo essas aprendizagens para dentro do novo grupo.

As categorias procuradas na análise se confundem com os papéis desempenhados pelos membros dos grupos e as práticas que as sustentam, e se apresentam como tarefas, comportamentos e atitudes no trabalho. Os ganhos de legitimidade e pertencimento são variáveis relevantes no processo de aprendizagem, e pode-se identificar que o processo de aprendizagem situada não ocorre somente em comunidades de prática, e que o pertencimento e a participação periférica legitimada são características a serem fomentadas nas organizações para que a cultura da aprendizagem constante se propague.

Abordaram-se, nesta pesquisa, um viés interpretativista e uma construção teórica baseada numa visão sociológica, de acordo com a linha epistemológica de Lave e Wenger (I99I). A pesquisa fundamentou-se na ontologia socioconstrucionista, partindo da premissa de que não há realidade objetiva a ser descoberta, uma vez que o ser humano constrói o conhecimento por meio de suas interações sociais. Do mesmo modo, com base na epistemologia socioconstrucionista, compreende-se o conhecimento como fragmentário, construído histórica e socialmente. Assim, as informações da pesquisa permitiram elucidar de que maneira a participação e legitimidade nas práticas de trabalho podem auxiliar na aprendizagem. 


\section{SITUATED LEARNING, PARTICIPATION AND LEGITIMACY IN THE WORK PRACTICES}

\section{ABSTRACT}

This study aims to identify and analyze the process of situated learning considering the participation and legitimacy in the practice of working groups of the Dublin Irish Pub. The theoretical framework involves the situated learning, together with the study of the legitimate peripheral participation and different levels of participation in the work practices of the working groups. We adopted the basic qualitative method, which aims to understand the meanings constructed by people. The data was collected using direct observation, field diary, interviews. The observation period of six months included thirty-two field trips and eight interviews. Thus, through interpretive analysis, the information elucidated how the legitimacy and participation in work practices can assist in learning. Among the findings in the study, we explain forms of collective learning that have emerged and established differences in the learning process situated in three working groups: waiters; bartenders, kitchen. Describing analytically the engagement and participation of learners in work practices and communities of practice, it is argued from this work that this process of acting on communities of practice involves the initial phase of legitimate peripheral participation, engagement and performance with the most experienced develops learning. Thus, legitimacy and belonging are important elements in the learning process. The process of situated learning occurs not only in communities of practice. It is relevant to observe that the membership as well as legitimate peripheral participation are features to be highlighted in organizations. With the negotiation and renegotiation of meanings, establishment of social relationships and communities of practice, it is developed a system which the ways of seeing, interpreting, understanding, practicing, are constituted and shared.

\section{KEYWORDS}

Situated learning; Participation; Work practices; Communities of practice; Legitimacy. 


\section{APRENDIZAJE SITUADA, PARTICIPACIÓN Y LEGITIMIDAD EN LAS PRÁCTICAS DE TRABAJO}

\section{RESUMEN}

Este estudio tiene como objetivo identificar y analizar el proceso de aprendizaje situada considerando la participación y la legitimidad en la práctica de grupos de trabajo del Dublin Irish Pub. El enfoque teórico consiste en la aprendizaje situada, junto con el estudio detallado de la participación periférica legítima y diferentes niveles de participación en las prácticas de trabajo de los grupos de trabajo. Hemos adoptado el método de base cualitativa. Los datos fueron recolectados por observación directa, diario de campo, entrevistas. En el período de observación de seis meses fueran treinta y dos viajes para la pesquisa de campo y ocho entrevistas en la empresa estudiada. Así, la información de la encuesta permite dilucidar cómo la legitimidad y la participación en las prácticas de trabajo pueden ayudar en el aprendizaje. Entre las conclusiones del estudio fueran identificadas e analisadas las formas de aprendizaje colectiva que han surgido y se estableció diferencias en el proceso de aprendizaje situado en tres grupos de trabajo: camareros, barmans y cocina. Al describir analíticamente el compromiso y la participación de las personas en prácticas de trabajo y comunidades de práctica, se argumenta a partir de este trabajo que en el proceso que pasa por la fase inicial de la participación periférica legítima, compromiso y rendimiento con los más experimentados se desarrolla el aprendizaje. Además, legitimidad y pertenencia son elementos importantes en el proceso de aprendizaje y puede identificar que el proceso de aprendizaje situada no sólo ocurre en las comunidades de práctica. Hay que destacar el sentimiento de pertenencia y la participación periférica legítima como características que se debe potenciar en las organizaciones. Con la negociación y renegociación de significados, el establecimiento de las relaciones sociales y de comunidades de práctica, se crea un sistema por el cual las formas de ver, interpretar, comprender, practicar, se constituyen y son compartidos.

\section{palabras clave}

Aprendizaje situado; Participación; Prácticas de trabajo; Comunidades de práctica; Legitimidad. 


\section{REFERÊNCIAS}

ANTONELLO, C. S. As formas de aprendizagem utilizadas por gestores no desenvolvimento de competências. In: ENCONTRO NACIONAL DOS PROGRAMAS DE PÓS-GRADUAÇÃO EM ADMINISTRAÇÃO - ENANPAD, 28., 2004, Curitiba.

ANTONELLO, C. S.; RUAS, R. Formação gerencial: pós-graduação lato sensu e o papel das comunidades de prática. Revista de Administração Contemporânea, v. 9, n. 2, p. 35-38, abr./jun. 2005.

BOGENRIEDER, I. Social architecture as a prerequisite for organizational learning. Management Learning, v. 33, n. 2, p. I97-212, June 2002.

BROWN, J.; DUGUID, P. Organizational learning and communities-of-practice. Organization Science, v. 2, n. I, p. 40-57, I99I.

GHERARDI, S.; NICOLINI, D.; ODELLA, F. Toward a social understanding of how people learn in organizations. Management Learning, v. 29, n. 3, p. 273-297, I998.

HANDLEY, K. et al. Researching situated learning: participation, identity and practices in clientconsultant relationships. Management Learning, v. 38, n. 2, p. I73-I9I, 2007.

HONG, J. F. L.; O, F. K. H. Conflicting identities and power between communities of practice: the case of IT Outsourcing. Management Learning, v. 40, n. 3, p. 3II-332, 2009.

LAVE, J. Situated learning in communities of practice. In: RESNICK, L.; LEVINE, J.; TEASLEY, S. (Ed.). Perspectives on socially shared cognition. Washington, DC: American Psychological Association, I991. p. 63-82.

LAVE, J. The practice of learning. In: CHAIKLIN, S.; LAVE, J. (Ed.). Understanding practice: perspetives on activity and context. Cambridge: Cambridge University Press, I993. p. 200-207.

LAVE, J.; WENGER, E. Situated learning: legitimate peripheral participation. Cambridge: Cambridge University Press, I99I.

LEE, S.; ROTH, W. M. Becoming and belonging: learning qualitative research through legitimate pheriferal participation. Forum: Qualitative Social Research/Forum Qualitative Sozialforschung, v. 4, n. 2, p. I-22, 2003.

MERRIAM, S. Qualitative research and case study application in education. San Francisco: JosseyBass, I998.

ROCHA, E.; BARROS, C.; PEREIRA, C. Fronteiras e limites: espaços contemporâneos da pesquisa etnográfica. In: LENGLER, J. F. B.; CAVEDON, N. R. (Org.). Pós-modernidade e etnografia nas organizações. Santa Cruz do Sul: Edunisc, 2005. p. 125-128.

RYAN, G. W.; BERNARD, H. R. Data management and analysis methods. In: DENZIN, N. K.; LINCOLN, Y. S. (Ed.). Handbook of qualitative research. 2. ed. Thousand Oaks: Sage, 2000.

SENSE, A. J.; BADHAM, R. J. Cultivating situated learning within project management practice: a case study exploration of the dynamics of project-based learning. International Journal of Managing Projects in Business, v. I, n. 3, p. 432-438, 2008.

SOUZA-SILVA, J. C. Condições e desafios ao surgimento de comunidades de prática em organizações. Revista de Administração de Empresas, v. 49, n. 2, p. I76-I89, abr./jun. 2009.

STURDY, A. et al. Management as a (self) confidence trick: management ideas, education and identity work. Organization, v. I3, n. 6, p. 84I-860, 2006. 
SVENSSON, L.; ELLSTRÖM, P.-E.; ÅBERG, C. Integrating formal and informal learning at work. The Journal of Workplace Learning, v. I6, n. 8, p. 479-49I, 2004.

SWAN, J.; SCARBROUGH, H.; ROBERTSON, M. The construction of communities of practice' in the management of innovation. Management Learning, v. 33, n. 4, p. 477-496, 2002.

TAYLOR, S. J.; BOGDAN, R. Introduction to qualitative research methods: the search for meanings. New York: John Wiley \& Sons, I984.

WENGER, E. Communities of practice: learning, meaning, and identity. New York: Cambridge University Press, I998.

Communities of practice and social learning systems. Organization, v. 7, n. 2, p. 225-246, 2000.

WENGER, E.; SNYDER, W. Communities of practice: the organizational frontier. Harvard Business Review, v. I8, n. I, p. I39-I46, 2000. 